\title{
A cross-generational comparison of smartphone addiction among Gen X and Gen Y smartphone users in Malaysia
}

\author{
Mohd Kamal Othman, Mohd Yasin Mohd Amin \\ Faculty of Cognitive Sciences and Human Development, Universiti Malaysia Sarawak, Sarawak, Malaysia
}

\begin{tabular}{l} 
Article Info \\
\hline Article history: \\
Received Aug 18, 2021 \\
Revised Nov 7, 2021 \\
Accepted Nov 19, 2021 \\
\hline
\end{tabular}

Keywords:

Cross-generational

Cyberspace-oriented relationship

Daily life disturbance

Positive anticipation

Smartphone addiction

Withdrawal

\begin{abstract}
This study reported the prevalence of smartphone addiction among Gen $\mathrm{X}$ and Gen Y in Sarawak, Malaysia. This study compared the two generations, $\mathrm{X}$ and $\mathrm{Y}$, on smartphone addictive behaviour. It is important to understand their addiction to smartphones. Two hundred thirty-six participants were recruited using a Facebook advertisement, consisting of 122 males and 114 females aged 16 to 55. The smartphone addiction scale-malay (SAS-M) was used to assess smartphone addiction. The data was analysed using IBM SPSS. The result shows that Gen Y is more addicted to a smartphone than Gen $\mathrm{X}$ for all components of SAS-M, but there is no significant difference between female and male users for both generations in smartphone usage. In addition, there is a significant difference in the cyberspace-oriented relationship between Gen X and Gen Y. Furthermore, Gen Y had lost control of the use of smartphones compared to Gen $X$, which reflects the overuse and primacy components that lead to daily life disturbances. Positive anticipation and withdrawal were also observed between the two generations. In conclusion, there is a significant difference between Gen $\mathrm{X}$ and Gen $\mathrm{Y}$ in smartphone addictive behaviour, implying that Gen $\mathrm{Y}$ is a more compulsive user than Gen $\mathrm{X}$. It is important to understand this addictive behaviour and provide an intervention measure to ensure that this will not become a psychological issue. The intervention measure is important to improve mental health and psychological wellbeing.
\end{abstract}

This is an open access article under the CC BY-SA license.

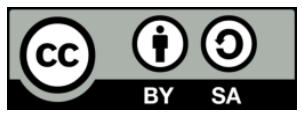

Corresponding Author:

Mohd Kamal Othman

Faculty of Cognitive Sciences and Human Development, Universiti Malaysia Sarawak

94300 Kota Samarahan, Sarawak, Malaysia

Email: omkamal@unimas.my

\section{INTRODUCTION}

Smartphone technologies have revolutionised how people interact with technology as well as with other people. A smartphone is made up of technologies that combine personal computer features with mobile technologies. These different features consist of a personal digital assistant (PDA), a media player, global positioning system (GPS), a touchscreen user interface, internet access, and a camera [1]. As individuals depend more on their mobile technology to do jobs and seek information or entertainment, smartphones have become an important tool in their daily lives, whether they are digital natives (Gen Y) or digital immigrants (Gen X). Gen X is born between 1965 and 1979, after baby boomers with birth dates ranging from 1965 to 1979, while Gen Y, also known as millennials, was born between 1980 and 1994.

Researchers suggested that the smartphone app usage between Gen $\mathrm{X}$ and $\mathrm{Y}$ is considerably different and related to the technology environment [2]. Digital media has given Gen Y the convenience of connecting to others and the world and becoming more knowledgeable [3]. Therefore, it can be implied that Gen Y is more techno-savvy than Gen X. It is suggested that Gen Y has a certain level of knowledge and skills in operating digital devices as a result of their upbringing in a technological environment and 
familiarity with computer syntax and language, video games, and internet services [4]. In addition, Gen Y users mainly use technologies to express themselves, find information, create an art form, and multitask, whilst Gen X users prefer the traditional analogue modes of communication, although they use the internet for email and search engines [5]. Thus, the situation reflected Gen Y internet usage for information seeking, socialising, and conducting business, whilst Gen X users tend to limit their internet usage for information seeking only. However, it should not create a bias to claim that Gen X does not have a similar experience to smartphone usage as compared to Gen Y. One of the issues highlighted in previous studies is the acceptance and adoption of smartphone technology due to the age factor, which leads to the excessive use of the smartphone. Previous study highlighted that one aspect affecting the use of information systems is age [6]. Despite the increase of internet usage between Gen X and Y, it is important to understand the differences in the types of activities which are different based on their preferences. The services provided on the smartphone allow developers to develop smartphone apps for different purposes. Lim [7] suggested that users preferred the smartphone app to visit websites. For example, social media platforms such as Twitter, Facebook, and Instagram are among the most preferred by gen $\mathrm{X}$ and $\mathrm{Y}$. In addition, the accessibility of realtime information, meeting new people, and entertainment is the main reason why gen $\mathrm{X}$ and $\mathrm{Y}$, are more attracted to social apps [8].

A total of $30.7 \%$ of Gen X were smartphone users who use social media monthly and seem to be more interested in digital video, whilst millennial smartphone users are at $32.9 \%$ and have the highest social networking penetration and are more active in digital video activities [9]. In addition, 80-90\% of gen X and Y use mobile apps weekly, particularly social media and gaming apps. Furthermore, 50-60\% of them favour their smartphones when searching for local information and utilising direction apps, especially on the go. Recently, it is revealed that Gen X made more phone calls in a day whilst Gen Y was more active on social media [10]. Thus, it reflected that the features of the smartphone could impact their use and addictive behaviour.

The smartphone's ability to ease fulfilment in different life aspects due to its sophistication and multifunctional uses has become a significant factor that enhances the urge to be hooked on their smartphones [11]. However, it has introduced different issues, such as smartphone addiction. For example, users are constantly checking their phones more often than before, there is less physical interaction between users, there is daily life activity disturbance, withdrawal syndrome, and many more. Previous research has highlighted the growing problems associated with smartphone addiction, such as physical, physiological, and performance issues [11]-[17]. In addition, Gutierrez et al. [18] correlated excessive internet usage (smartphone abuse) with a sleep deficit, stress, anxiety, and depression. Furthermore, a study suggested that depression and anxiety are strongly correlated with smartphone addiction [19].

The wide access to the smartphone apps provided in the market (Google Play or App Store) led to the excessive use of smartphones amongst Gen X and Y. Thus, it is vital to identify the smartphone technology's effect on users. Users have different behaviour towards smartphone usage, and it is related to their needs, interests, and situational contexts [20]. In addition, the behavioural intention and attitude towards using smartphones depend on the smartphone's perceived usefulness [21]. Behavioral control and intention are related directly to perceived usefulness (except for games) and perceived enjoyment [22], [23]. Both of these determine user attitudes towards smartphones [24]. In addition, the previous study suggested that the intention of using a smartphone for activities such as mobile shopping has a positive impact on enjoyment amongst the purchasers [22].

According to [25], there are 28.36 million smartphone users in Malaysia in 2021, with the number expected to rise to 29 million in 2021. It is suggested that the Gen Y has different learning styles from Gen X [26]. They further added that digital natives have complex and flexible knowledge of information technology, whilst the younger generation tend to explore technology services due to their curiosity. Therefore, smartphone addiction differs between generations, and previous studies suggested that Gen Y had greater addictive behaviour than Gen $\mathrm{X}$ and $\mathrm{Z}$ [27]. They further added that the main factors contributing to addictive behaviour are social pressure and emotional gain. This echoed earlier research suggesting that the mechanism of social influence is why individuals embrace or reject the new system [28].

Currently, no known study examines the cross-generational analysis of smartphone addiction's prevalence in the Malaysian context. The previous study used the smartphone addiction scale-Malay (SASM) to measure smartphone addiction and internet addiction amongst multi-ethnic medical students in Malaysia [29]. In contrast, this study explores the prevalence of smartphone addiction among Gen $\mathrm{X}$ and $\mathrm{Y}$ in Sarawak. It further measures the impact of smartphone addiction between generations and gender using the smartphone addiction scale (SAS-M). The difference in gender between generations is very important to be assessed and examined. It is important to find out the correlation between male and female addiction to smartphone use. The gender difference needs to be measured in terms of cross-generation and within the same generation. The diversity in smartphone usage between generations might provide different insights into how they perceive smartphone use. 


\section{RESEARCH METHOD}

An observational study was utilised to understand the smartphone addiction among Gen $\mathrm{X}$ and $\mathrm{Y}$ in Sarawak, Malaysia. An observational study utilising an online survey was used in this study. A targeted user (either Gen X or Y) was recruited to participate in this study. Two hundred thirty-six participants, consisting of 122 males and 114 females, aged 16 to 55 years old, participated in this study after they responded to the Facebook Ads. As this study involved human participants, the ethical procedure from the Research Committee Board at Universiti Malaysia Sarawak was appropriately followed throughout the research.

The smartphone addiction scale-Malay (SAS-M) measured smartphone addiction between generations $\mathrm{X}$ and $\mathrm{Y}$. The SAS-M is a self-completed questionnaire consists of 33 items using a 6-point Likert type scale, ranging from 1 to $6(1=$ strongly agree to $6=$ strongly disagree). This scale item reflects the smartphone addiction symptoms and the higher score reflects the compulsive use of the smartphone. This SAS-M scale consists of six components: cyberspace-oriented relationship, daily life disturbance, primacy, overuse, positive anticipation, and withdrawal. Ching et al. [29] described the differences between the original SAS and SAS-M components, which could be the cultural differences between samples used in both Korea and Malaysia. The original SAS comprises five components: daily life disturbance, positive anticipation, withdrawal, cyberspace-oriented relationship, overuse and tolerance. One of the reasons for the difference in primacy and tolerance components could be attributed to the different subjects investigated in terms of their occupation and education level involved in the original SAS study. The validation of the instrument (SAS-M) used in this study can be referred to [29]. Participants in this study volunteered and were not rewarded with monetary or any rewards for their participation. They were recruited using a Facebook advertisement for two-month duration. Participants in this study were provided with a link to a Google Forms consisting of several items to be completed, such as the informed consent form, demographic information such as age, gender, and the SAS-M instruments. All information provided in this study is kept confidential.

\section{RESULTS}

Table 1 depicts the respondents' demographic profiles in this study for each group. An independentsample t-test conducted to compare smartphone addiction in Gen X and Gen Y in this study shows that there was a significant difference in smartphone addiction between $\mathrm{Gen} X(\mathrm{M}=2.77, \mathrm{SD}=0.55)$ and $\mathrm{Gen} \mathrm{Y}$ $(\mathrm{M}=3.68, \mathrm{SD}=0.84) ; \mathrm{t}(234)=9.64, \mathrm{p}=0.00$. It is suggested that $\mathrm{Gen} \mathrm{Y}$ is more addicted to smartphones than Gen X. In addition, results show that Gen Y is more addicted to a smartphone than Gen X for all SAS-M components. Furthermore, a further analysis yielded the following findings:

a. There was a significant difference in the cyberspace-oriented relationship between Gen $X(M=2.68$, $\mathrm{SD}=0.77)$ and Gen $\mathrm{Y}(\mathrm{M}=3.54, \mathrm{SD}=0.97) ; \mathrm{t}(234)=7.39, \mathrm{p}=0.00$. This result shows that Gen $\mathrm{Y}$ had more connected feelings with real life friends using the smartphone as a medium compared to Gen $\mathrm{X}$.

b. There was a significant difference in the daily life disturbance between Gen $X(M=3.08, S D=0.66)$ and Gen Y $(M=3.67, S D=0.91) ; \mathrm{t}(234)=5.48, \mathrm{p}=0.00$. The finding insinuated that Gen $\mathrm{Y}$ was not able to concentrate or have issues with daily tasks due to their attachment to smartphones as compared to Gen X.

c. There was a significant difference in the primacy between Gen $\mathrm{X}(\mathrm{M}=2.60, \mathrm{SD}=0.84)$ and Gen $\mathrm{Y}$ $(\mathrm{M}=3.64, \mathrm{SD}=0.96) ; \mathrm{t}(234)=8.75, \mathrm{p}=0.00$. The finding implied that Gen $\mathrm{Y}$ is constantly checking their smartphones to get more updates or new notifications as compared to Gen X.

d. There was a significant difference in the overuse between Gen $\mathrm{X}(\mathrm{M}=2.71, \mathrm{SD}=0.72)$ and Gen $\mathrm{Y}$ $(\mathrm{M}=3.82, \mathrm{SD}=0.97)$; $\mathrm{t}(234)=9.80, \mathrm{p}=0.00$. The finding shows that Gen $\mathrm{Y}$ are using smartphones excessively and are not able to control their usage as compared to Gen X.

e. There was a significant difference in the positive anticipation between Gen $X(M=3.07, S D=0.90)$ and Gen Y $(M=3.89, \mathrm{SD}=1.02) ; \mathrm{t}(234)=6.456, \mathrm{p}=0.00$. The finding suggested that $\mathrm{Gen} \mathrm{Y}$ is deeply attached to the smartphone and feel uneased if are not using the smartphone as compared to Gen $\mathrm{X}$.

f. There was a significant difference in the withdrawal between $\mathrm{Gen} X(\mathrm{M}=2.45, \mathrm{SD}=0.87)$ and Gen $\mathrm{Y}$ $(\mathrm{M}=3.53, \mathrm{SD}=1.05) ; \mathrm{t}(234)=8.47, \mathrm{p}=0.00$. The finding shows that Gen $\mathrm{X}$ is constantly thinking about smartphones as compared to Gen Y.

An independent-sample t-test to compare smartphone addiction in males and females shows that there was no significant difference in smartphone addiction between males $(\mathrm{M}=3.35, \mathrm{SD}=0.87)$ and females $(\mathrm{M}=3.16, \mathrm{SD}=0.83) ; \mathrm{t}(234)=1.70, \mathrm{p}=0.089$. It is suggested that both males and females were equally addicted to the smartphone. Furthermore, a gender analysis of Gen X smartphone addiction revealed that there was no significant difference in smartphone addiction between male Gen $\mathrm{X}(\mathrm{M}=2.58, \mathrm{SD}=0.80)$ and female Gen $X(M=2.74, S D=0.75) ; t(106)=-1.09, p=0.278$. A similar result also appears between males and females in Gen $\mathrm{Y}$ conditions, as there was no significant difference in smartphone addiction in males $(\mathrm{M}=3.61, \mathrm{SD}=0.93)$ and females $(\mathrm{M}=3.44, \mathrm{SD}=1.04) ; \mathrm{t}(128)=0.91, \mathrm{p}=0.362$. 


\begin{tabular}{cclcc} 
Table 1. Respondents' demographic profile \\
\cline { 2 - 5 } \multicolumn{2}{c}{ Generation X } & \multicolumn{2}{c}{ Generation Y } & Total \\
\hline Males & 43 & Males & 80 & 123 \\
Females & 64 & Females & 49 & 113 \\
Total & 107 & Total & 129 & 236 \\
\hline
\end{tabular}

\section{DISCUSSION}

The result shows that Gen $\mathrm{Y}$ is more addicted to smartphones in Sarawak than Gen X, and the results show significant differences between these two groups. Furthermore, this result corroborates the assumption that Gen $\mathrm{X}$ is less addicted than Gen $\mathrm{Y}$ because of their digital immigrant and native status. Gen $\mathrm{Y}$ shows its ability to adapt to new technology and is more familiar with digital devices [1]. Thus, they tend to exploit state-of-the-art technology such as smartphones in their daily activities and workplace. In addition, technology has a significant impact and plays an integral role in Gen Y's lives, and they are more curious about exploring new technology [26].

Furthermore, a recent study suggested that Gen Y shows more addictive behaviour than Gen X and $\mathrm{Z}$ [27]. They further explained that the reason for this overuse and addictive behaviour for Gen $\mathrm{Y}$ is the transition from limited access/lack of access to the high availability of the technology. A previous study revealed that Gen $\mathrm{Y}$ users are more at risk of smartphone addiction [30]. In addition, 50\% of India's population who use smartphones are from Gen Y and are below 25 years old [31]. This is due to several factors, such as the nature of communication, readiness to buy, media consumption, and brand influence or consciousness. In addition, they are willing to spend their money on a smartphone that provides various functions rather than solely as a communication tool.

Also, Gen $\mathrm{Y}$ is more inclined to use new technology such as smartphones and trending apps, contributing to their addictive behaviour. Thus, it can be concluded that Gen $\mathrm{Y}$ is more proficient and attracted to smartphones than Gen $\mathrm{X}$ because they are pleased with the smartphone functionality. Exposure to technology is another important factor in depicting the addictive behaviour towards smartphones shown by Gen Y. The smartphone also has an important role in shaping Gen Y life stages: lifestyle, attitude, and character. Furthermore, the product promotion through different media focuses on Gen Y's generational values compared to Gen X, thus reflecting Gen Y's addictive behaviour towards smartphones [32]. The difference in the adaptation of smartphones between generations is due to Gen $\mathrm{Y}$ being a digital native and living their lives surrounding technology compared to Gen X. Therefore, there is a gap in using the smartphone apps for both generations [2].

This study echoed a previous study [31], which showed that there is no significant difference in smartphone addiction behaviour between genders, although previous studies (i.e. [29], [33]-[35]) suggested that smartphone addictive behaviour between genders is significant. In addition, Hwang et al. [36] have suggested that male participants are less addicted to smartphones. Our study shows similar results to a study conducted in Israel. On the other hand, our study shows different findings as compared to the studies conducted in several European countries and Canada. Therefore, we assumed that it was due to cultural differences amongst participants where these different studies were conducted and the personality traits that contributed to the demographics of participants in each study. Furthermore, the findings suggested that it could be due to social environment pressure and the purpose of using the smartphone (i.e., for social networking), both of which lead to social and content gratification.

A cyberspace-oriented relationship can be described as intimate feelings with real-life friends. Users virtually use the smartphone and have uncontrollable feelings of loss when they are unable to use or constantly check on the smartphone [30]. For example, users might miss the familiarity of contacting friends using social platforms such as Facebook and Twitter. Findings from this study show that Gen Y is more attached to their real world friends using the smartphone as compared to Gen X. However, a further analysis for both females and males between generations and within generations shows no significant difference in cyberspace-oriented relationship component.

A recent study shows that smartphone dependence is a better term to describe smartphone addiction, and it can be divided into two types, functional and existential [37]. Participants in the study expressed concern about being cut off from people and the network. The cyber-oriented relationship used in the current study can be related to existential dependence because users are compulsively checking their online status [38]. Although the study above did not specifically describe its participants' demographic details, it shows how smartphones impact users' behaviour regardless of their generation. Some users think that smartphones are part of their lives, and it becomes difficult to detach themselves [39].

The daily life disturbance component in this study refers to the issues related to the disturbance or disruption of planned work or inability to concentrate while performing a task. In addition, it also focuses on minor physiological symptoms such as light-headedness, blurred visions, wrist or neck pains, and any sleeping disturbance. Some users cannot concentrate on performing the tasks due to constantly thinking about 
the smartphone and cannot get it out of their minds. Analysis of the component shows that there is a significant difference between Gen X and Y. However, a further analysis of Gen X and Y between genders shows no significant differences, while analysis between genders for each generation also shows no significant differences for the daily life disturbance component. The findings indicated that both genders have similar addictive behaviour. A previous study shows that there is a positive correlation between daily life disturbance and social, emotional distress (e.g. anxiety, depression), poor sleep quality, poor general daily functioning, poor interpersonal relationships (e.g. conflicts, loneliness) [40]. The results echoed the previous studies [41]-[45].

The primacy component can be described as a preference of new information over old information by the brain [37]. For example, a smartphone's ability to provide a constant and live update for all activities prompted an excitement or nervousness when the notification arrived or the feeling of urgency to constantly check the smartphone. Findings from this study show that there is a significant difference between Gen $\mathrm{X}$ and Y. However, a further analysis between genders for between-generations shows no significant difference for this component. Furthermore, analysis between genders for each generation shows no significant difference for the primacy component. In 2015, $76 \%$ of internet users visited Facebook on a daily basis, 55\% visited several times per day, and $22 \%$ visited the site daily [46].

The overuse component is the inability to control smartphone use even for a short period and the users' preference to use a smartphone for completing any task [37]. This study suggests that Gen Y shows significant additive behaviour for overused components as compared to Gen X. In addition, further analysis shows that no differences were found in the overuse component for males and females between generations and within generations. Previous studies have suggested that the overuse of smartphones may lead to negative impacts such as stress, anxiety, and depression [47], and social anxiety [48].

Positive anticipation can be described as excitement (feeling), emptiness (without a smartphone), or distress when using a smartphone. Smartphones can be used to promote enjoyment and alleviate stress [37]. It diminishes any sense of anxiousness or exhaustion. Findings from this study show that both generations exhibit similar addictive behaviour in this component, which is similar to the study by Youn et al. [49]. A subsequent analysis, however, found no difference in addictive behavior (positive anticipation component) between males and females within generation and between generations.

The withdrawal component can describe the users' condition when constantly thinking about a smartphone, being impatient without a smartphone, and the continuous habit of not giving up or being bothered when using a smartphone [37]. In this study, Gen Y users in Malaysia are actively engaged with smartphone usage as compared to Gen X, which shows that they show addictive behaviour. Findings from this study also show a similar pattern to a cross-generational analysis study conducted by Youn et al. [49] which suggested a significant difference between the withdrawal component rated by the adolescents and their parents in Korea. A further analysis also revealed that no significant difference was recorded between gender for each generation for the withdrawal component, which suggested that males and females share the same behaviour.

\section{CONCLUSION}

A smartphone is one of the most used gadgets among Malaysians, thus raising concern about their smartphone addiction. This study examines smartphone addiction among Gen $\mathrm{X}$ and Gen $\mathrm{Y}$ using the smartphone addiction scale-Malay (SAS-M). The findings show a significant difference between Gen X and Gen $\mathrm{Y}$ in smartphone addictive behaviour, suggesting that Gen $\mathrm{Y}$ is more compulsive users than Gen $\mathrm{X}$. Therefore, Gen Y has a wider mobile predisposition and is attached to mobile technology in their daily lives. In addition, results also show no significant difference in smartphone usage by female and male users for both generations or within generations. Thus, it implied that they are equally addicted to the smartphone. It is important to understand this addictive behaviour and provide an intervention measure to ensure that this will not become a psychological issue.

This study used the SAS-M, which was initially developed to measure smartphone addiction among medical students. Although this might not be the perfect instrument for measuring smartphone addiction amongst Gen $\mathrm{X}$ and $\mathrm{Y}$, the six components that make up the SAS-M used in the scale can reflect the pathological behaviour of smartphone users and show similar results to previous research. Furthermore, both studies provide insights to healthcare providers about the current state of additive behaviour among Gen $\mathrm{X}$ and $\mathrm{Y}$, which can lead to a better intervention in mitigating the issues. The limitation of this study is that it only focused on the users using Facebook because the recruitment of participants is made online. In addition, the sample size provided in this study may be adequate for the research but not sufficiently randomised because the gender and race were not equally distributed. The sample population might also be homogenous and single centred (in Sarawak only). Therefore, it cannot reflect the general population in Malaysia.

We believed that the initial study of SAS-M's acts as an assessment scale of the severity of smartphone addiction rather than a diagnostic tool. As a result, future work should consider including demographic criteria 
such as functional impairment due to smartphone use and the exclusion of psychiatric disorders are included for the subject sample. Elimination of these subjects that fulfil these criteria can provide a narrower and more specific conclusion on smartphone addiction between Gen $\mathrm{X}$ and $\mathrm{Y}$. The removal of these samples will provide a better understanding of the cross-generational analysis of smartphone addiction and, as a result, will inform the healthcare professional about the best type of intervention.

\section{REFERENCES}

[1] A. Nusca, "Smartphone vs. feature phone arms race heats up; which did you buy?" https://www.zdnet.com/article/smartphone-vsfeature-phone-arms-race-heats-up-which-did-you-buy/ (accessed Nov. 18, 2015).

[2] R. Gafni and N. Geri, "Generation Y versus Generation X: Differences in Smartphone Adaptation," Proceedings of the 8th Chais Conference on Innovation and Learning Technologies, pp. 18-23, 2013

[3] S. Saatchi, Landmark Study Discovers Connexity Kids. London: Saatchi \& Saatchi Press Release, 1999.

[4] M. Prensky, "Digital Natives, Digital Immigrants Part 1," On the Horizon, vol. 9, no. 5, pp. 1-6, 2001, doi: $10.1108 / 10748120110424816$

[5] J. G. Palfrey and U. Gasser, Born Digital: Understanding The First Generation of Digital Natives. New York: Basic Books, 2011.

[6] V. Venkatesh, J. Y. L. Thong, and X. Xu, "Consumer acceptance and use of information technology: Extending the unified theory of acceptance and use of technology," MIS Quarterly: Management Information Systems, vol. 36, no. 1, pp. 157-178, 2012, doi: $10.2307 / 41410412$.

[7] J. B. Y. Lim, "Mobile media and youth engagement in Malaysia," in Interdisciplinary Mobile Media and Communications: Social, Political, and Economic Implications, 2014, pp. 139-156.

[8] T. K. H. Chan, C. M. K. Cheung, Z. W. Y. Lee, and T. Neben, "The urge to check social networking sites: Antecedents and consequences," Proceedings - Pacific Asia Conference on Information Systems, PACIS 2014, 2014.

[9] "Digital Advertising Trends for 2013-eMarketer." 2013, https://www.emarketer.com/Webinar/Digital-Advertising-Trends2013/4000064 (accessed Jun. 28, 2018).

[10] D. J. Kuss, E. Kanjo, M. Crook-Rumsey, F. Kibowski, G. Y. Wang, and A. Sumich, "Problematic Mobile Phone Use and Addiction Across Generations: the Roles of Psychopathological Symptoms and Smartphone Use," Journal of Technology in Behavioral Science, vol. 3, no. 3, pp. 141-149, Sep. 2018, doi: 10.1007/s41347-017-0041-3.

[11] A. Greenfield, "Everyware: The dawning age of ubiquitos computing." Los Angeles: New Riders, 2010. http://www.studiesobservations.com/everyware/samples/everyware thesis01.pdf (accessed Jan. 18, 2020).

[12] S. Thomée, A. Härenstam, and M. Hagberg, "Mobile phone use and stress, sleep disturbances, and symptoms of depression among young adults - A prospective cohort study," BMC Public Health, vol. 11, no. 1, p. 66, Dec. 2011, doi: 10.1186/1471-2458-11-66.

[13] L. Reinecke et al., "Digital Stress over the Life Span: The Effects of Communication Load and Internet Multitasking on Perceived Stress and Psychological Health Impairments in a German Probability Sample," Media Psychology, vol. 20, no. 1, pp. 90-115, Jan. 2017, doi: 10.1080/15213269.2015.1121832

[14] S. Parasuraman, A. Sam, S. K. Yee, B. C. Chuon, and L. Ren, "Smartphone usage and increased risk of mobile phone addiction: A concurrent study," Int. J. Pharmaceutical Investigation, vol. 7, no. 3, p. 125, 2017, doi: 10.4103/jphi.jphi_56_17.

[15] C.-H. Ko, J.-Y. Yen, C.-F. Yen, C.-S. Chen, and C.-C. Chen, "The association between Internet addiction and psychiatric disorder: A review of the literature," European Psychiatry, vol. 27, no. 1, pp. 1-8, Jan. 2012, doi: 10.1016/j.eurpsy.2010.04.011.

[16] K. S. Young and R. C. Rogers, "The relationship between depression and internet addiction," Cyberpsychology and Behavior, vol. 1, no. 1, pp. 25-28, Jan. 1998, doi: 10.1089/cpb.1998.1.25.

[17] C. Jenaro, N. Flores, M. Gómez-Vela, F. González-Gil, and C. Caballo, "Problematic internet and cell-phone use: Psychological, behavioral, and health correlates," Addiction Research and Theory, vol. 15, no. 3, pp. 309-320, Jan. 2007, doi: $10.1080 / 16066350701350247$.

[18] J. D. S. Gutiérrez, F. R. de Fonseca, and G. Rubio, "Cell-phone addiction: A review," Frontiers in Psychiatry, vol. 7, no. OCT, Oct. 2016, doi: 10.3389/fpsyt.2016.00175.

[19] J. Matar Boumosleh and D. Jaalouk, "Depression, anxiety, and smartphone addiction in university students- A cross sectional study," PLoS ONE, vol. 12, no. 8, p. e0182239, Aug. 2017, doi: 10.1371/journal.pone.0182239.

[20] T.-M.-T. Do and D. Gatica-Perez, "By their apps you shall understand them: mining large-scale patterns of mobile phone usage," in Proceedings of the 9th International Conference on Mobile and Ubiquitous Multimedia - MUM '10, 2010, pp. 1-10, doi: $10.1145 / 1899475.1899502$.

[21] Y. Park and J. V. Chen, "Acceptance and adoption of the innovative use of smartphone," Industrial Management and Data Systems, vol. 107, no. 9, pp. 1349-1365, Nov. 2007, doi: 10.1108/02635570710834009.

[22] S. Agrebi and J. Jallais, "Explain the intention to use smartphones for mobile shopping," Journal of Retailing and Consumer Services, vol. 22, pp. 16-23, Jan. 2015, doi: 10.1016/j.jretconser.2014.09.003.

[23] M. Z. Islam, P. K. C. Low, and I. Hasan, "Intention to use advanced mobile phone services (AMPS)," Management Decision, vol. 51, no. 4, pp. 824-838, Apr. 2013, doi: 10.1108/00251741311326590.

[24] H. Verkasalo, C. López-Nicolás, F. J. Molina-Castillo, and H. Bouwman, "Analysis of users and non-users of smartphone applications," Telematics and Informatics, vol. 27, no. 3, pp. 242-255, Aug. 2010, doi: 10.1016/j.tele.2009.11.001.

[25] J. Müller, "Smartphone Users in Malaysia 2020-2025," 2021. https://www.statista.com/statistics/494587/smartphone-users-inmalaysia/ (accessed Sep. 05, 2020).

[26] S. Bennett, K. Maton, and L. Kervin, "The 'digital natives' debate: A critical review of the evidence," British Journal of Educational Technology, vol. 39, no. 5, pp. 775-786, Sep. 2008, doi: 10.1111/j.1467-8535.2007.00793.x.

[27] M. Zhitomirsky-Geffet and M. Blau, "Cross-generational analysis of predictive factors of addictive behavior in smartphone usage," Computers in Human Behavior, vol. 64, pp. 682-693, Nov. 2016, doi: 10.1016/j.chb.2016.07.061.

[28] S. Kulviwat, G. C. Bruner, and O. Al-Shuridah, "The role of social influence on adoption of high tech innovations: The moderating effect of public/private consumption," Journal of Business Research, vol. 62, no. 7, pp. 706-712, Jul. 2009, doi: 10.1016/j.jbusres.2007.04.014.

[29] S. M. Ching et al., "Validation of a Malay version of the smartphone addiction scale among medical students in Malaysia," PLoS ONE, vol. 10, no. 10, p. e0139337, Oct. 2015, doi: 10.1371/journal.pone.0139337.

[30] M. Kwon et al., "Development and Validation of a Smartphone Addiction Scale (SAS)," PLoS ONE, vol. 8, no. 2, p. e56936, Feb. 2013, doi: 10.1371/journal.pone.0056936.

[31] Varsha Jain and Saumya Pant, "Navigating Generation Y for Effective Mobile Marketing in India,” Ijmm, vol. 7, no. 3, pp. 56-66, 2012. 
[32] K. C. Williams, R. A. Page, A. Petrosky, and E. H. Hernandez, "Multi-general marketing: Descriptions, characeristics, lifestyles and attitudes," Journal of Applied Business and Economics, vol. 11, no. 2, p. 21, 2010.

[33] A. J. A. M. Van Deursen, C. L. Bolle, S. M. Hegner, and P. A. M. Kommers, "Modeling habitual and addictive smartphone behavior: The role of smartphone usage types, emotional intelligence, social stress, self-regulation, age, and gender," Computers in Human Behavior, vol. 45, pp. 411-420, Apr. 2015, doi: 10.1016/j.chb.2014.12.039.

[34] O. Lopez-Fernandez et al., "Self-reported dependence on mobile phones in young adults: A European cross-cultural empirical survey," Journal of Behavioral Addictions, vol. 6, no. 2, pp. 168-177, Jun. 2017, doi: 10.1556/2006.6.2017.020.

[35] N. Shaw, "The mediating influence of trust in the adoption of the mobile wallet," Journal of Retailing and Consumer Services, vol. 21, no. 4, pp. 449-459, Jul. 2014, doi: 10.1016/j.jretconser.2014.03.008.

[36] H. S. Hwang, S. H. Shon, and Y. J. Choi, "Exploring Factors Affecting Smart-phone Addiction-Characteristics of Users and Fuctional Atributes," Korean Journal of Broadcasting and Telecommunication Studies, vol. 25, no. 2, pp. $277-313,2011$.

[37] C. S. Park, "Examination of smartphone dependence: Functionally and existentially dependent behavior on the smartphone," Computers in Human Behavior, vol. 93, pp. 123-128, Apr. 2019, doi: 10.1016/j.chb.2018.12.022.

[38] Z. Hussain, M. D. Griffiths, and D. Sheffield, "An investigation into problematic smartphone use: The role of narcissism, anxiety, and personality factors," Journal of Behavioral Addictions, vol. 6, no. 3, pp. 378-386, Aug. 2017, doi: 10.1556/2006.6.2017.052.

[39] C. S. Park and B. K. Kaye, "Smartphone and self-extension: Functionally, anthropomorphically, and ontologically extending self via the smartphone," Mobile Media and Communication, vol. 7, no. 2, pp. 215-231, May 2019, doi: 10.1177/2050157918808327.

[40] A. M. Volungis, M. Kalpidou, C. Popores, and M. Joyce, "Smartphone Addiction and Its Relationship with Indices of SocialEmotional Distress and Personality," International Journal of Mental Health and Addiction, vol. 18, no. 5, pp. 1209-1225, Oct. 2020, doi: 10.1007/s11469-019-00119-9.

[41] E. Emirtekin, S. Balta, İ. Sural, K. Kircaburun, M. D. Griffiths, and J. Billieux, "The role of childhood emotional maltreatment and body image dissatisfaction in problematic smartphone use among adolescents," Psychiatry Research, vol. 271, pp. 634-639, Jan. 2019, doi: 10.1016/j.psychres.2018.12.059.

[42] Y. J. Kim, H. M. Jang, Y. Lee, D. Lee, and D. J. Kim, "Effects of internet and Smartphone addictions on depression and anxiety based on propensity score matching analysis," International Journal of Environmental Research and Public Health, vol. 15, no. 5, p. 859, Apr. 2018, doi: 10.3390/ijerph15050859.

[43] A. Enez Darcin, S. Kose, C. O. Noyan, S. Nurmedov, O. Y1lmaz, and N. Dilbaz, "Smartphone addiction and its relationship with social anxiety and loneliness," Behaviour and Information Technology, vol. 35, no. 7, pp. 520-525, Jul. 2016, doi: 10.1080/0144929X.2016.1158319.

[44] K. Demirci, M. Akgönül, and A. Akpinar, "Relationship of smartphone use severity with sleep quality, depression, and anxiety in university students," Journal of Behavioral Addictions, vol. 4, no. 2, pp. 85-92, Jun. 2015, doi: 10.1556/2006.4.2015.010.

[45] J. Y. Mok et al., "Latent class analysis on internet and smartphone addiction in college students," Neuropsychiatric Disease and Treatment, vol. 10, pp. 817-827, May 2014, doi: 10.2147/NDT.S59293.

[46] S. Greenwood, A. T. Perrin, and M. Duggan, "Social Media Update 2016," Pew Research Center, vol. 11, no. 2, pp. 1-18, 2016, [Online]. Available: www.pewinternet.org/2016/11/11/social-media-update-2016/ (accessed Jul. 28, 2018)

[47] J. D. Elhai, R. D. Dvorak, J. C. Levine, and B. J. Hall, "Problematic smartphone use: A conceptual overview and systematic review of relations with anxiety and depression psychopathology," Journal of Affective Disorders, vol. 207, pp. 251-259, Jan. 2017, doi: 10.1016/j.jad.2016.08.030.

[48] J. Harwood, J. J. Dooley, A. J. Scott, and R. Joiner, "Constantly connected - The effects of smart-devices on mental health," Computers in Human Behavior, vol. 34, pp. 267-272, May 2014, doi: 10.1016/j.chb.2014.02.006.

[49] H. C. Youn et al., "Exploring the differences between adolescents' and parents' ratings on adolescents' smartphone addiction," Journal of Korean Medical Science, vol. 33, no. 52, 2018, doi: 10.3346/jkms.2018.33.e347.

\section{BIOGRAPHIES OF AUTHORS}

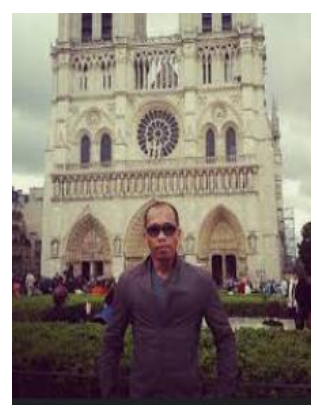

Mohd Kamal Othman (iD SC SC is an Associate Professor in the Faculty of Cognitive Sciences and Human Development at the Universiti Malaysia Sarawak. He received his Ph.D. in Computer Science (Human-Computer Interaction) from the University of York UK and a Master's degree in Virtual Environment: Technology and Practices from the University of East Anglia (UEA), UK. His research interest is multidisciplinary, ranging from Cognitive Science, Human-Computer Interaction, Computer Science, Virtual Reality, Artificial Intelligence, and Learning Science and Education. He can be contacted at email: omkamal@unimas.my.

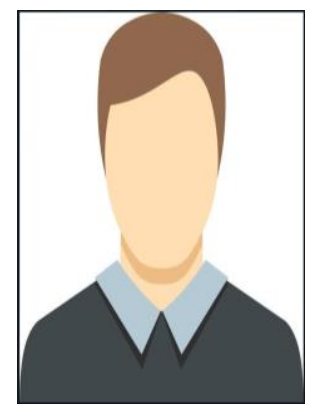

Mohd Yasin Mohd Amin (D) 81 SC P received his Corporate Master in Business Administration (CMBA) from Universiti Malaysia Sarawak. He completed his BSc in Cognitive Science from the same University. He can be contacted at email 37145@siswa.unimas.my. 